\title{
Overexpression of $A t B B X 29$ Improves Drought Tolerance by Maintaining Photosynthesis and Enhancing the Antioxidant and Osmolyte Capacity of Sugarcane Plants
}

\author{
Nelisa Mbambalala ${ }^{1} \cdot$ Sanjib K. Panda ${ }^{2}$ Christell van der Vyver $^{1}$ (D) \\ Received: 8 April 2020 / Accepted: 6 November 2020 / Published online: 11 November 2020 \\ (C) The Author(s) 2020
}

\begin{abstract}
B-box proteins have emerged as prominent mechanisms for controlling growth and developmental processes and in some instances responses to biotic and abiotic stresses in plants. These proteins mediate transcriptional regulations and proteinprotein interactions in cellular signalling processes. B-box proteins thereby play an important role in coordinating physiological and biochemical pathway flux and are therefore ideal targets for controlling stress responses in plants. In this study, the overexpression of an Arabidopsis thaliana B-box gene (BBX29) in sugarcane (Saccharum spp. hybrid) has led to enhanced drought tolerance and delayed senescence under water-deficit conditions when compared to the wild-type plants. Transgenic plants maintained a higher relative water content and better protected its photosynthetic machinery. These plants accumulated more proline and displayed enhanced enzymatic antioxidant activity under drought conditions. Overexpression of $A t B B X 29$ further alleviated the build-up of reactive oxygen species and curtailed oxidative damage, resulting in transgenic plants with improved health and higher survival rates during dehydration. Our results suggested that the $A t B B X 29$ gene influenced an array of physiological and biochemical mechanisms in sugarcane to the advantage of the crop and might be a target to genetically engineer drought tolerance into sugarcane. This is the first report to elucidate B-box protein functionality in a polyploid crop such as sugarcane.
\end{abstract}

Keywords Sugarcane $\cdot$ BBX $\cdot$ B-box proteins $\cdot$ Drought $\cdot$ Abiotic stress $\cdot$ Drought tolerance $\cdot$ Transcription factors

\section{Introduction}

Sugarcane (Saccharum spp. hybrid) is one of the most important crops in the world, grown mostly for its high sucrose content and as an important biomass source for biofuel production. Sugarcane is a very productive but high waterdemanding crop, and its growth and sugar content are

\section{Key Message}

- AtBBX29 overexpression impart drought tolerance in sugarcane by limiting oxidative damage, enhancing antioxidant scavenging activities, increasing osmotic adjustment substrates and maintaining stomatal conductance and the chlorophyll fluorescence rate.

Christell van der Vyver

cvdv@sun.ac.za

1 Institute for Plant Biotechnology, Stellenbosch University, Private Bag X1, Matieland, Stellenbosch 7601, South Africa

2 Department of Biochemistry, Central University of Rajasthan, Rajasthan 305817, India restricted by drought (Inman-Bamber and Smith 2005). Global climate change is causing frequent and severe drought spells worldwide, which became especially prevalent over the past decade in regions such as southern Africa (Nhamo et al. 2019). Therefore, sustainable production through induced tolerance towards limited water resources is of significant importance in this crop (Kumar et al. 2014).

The complexity of the sugarcane genome makes trait improvements through conventional breeding challenging; therefore, the alternative use of genetic engineering may contribute towards the sustainable production of this crop (Gentile et al. 2015; Piperidis et al. 2010). Stress tolerance in plants is controlled by the ever-evolving diverse physiological and biochemical strategies that involve differential expression of genes in pathways related to stress responses ( $\mathrm{Li}$ et al. 2016). Transcription of these genes is mainly controlled by regulatory genes, such as transcription factors (TFs), which can act as molecular switches by binding to conserved cisacting elements in promoter regions of target stress response genes, leading to enhanced stress tolerance (Gahlaut et al. 
2016). Genetic engineering can target these regulatory genes in order to potentially generate drought-tolerant sugarcane varieties and can contribute to enhancing our understanding of the linked pathways in plant abiotic stress tolerance (Bartels and Sunkar 2005).

BBX proteins' nomenclature was set to represent a subgroup of the zinc finger protein family, characterised by one or two conserved B-box domains and stabilised by specialised tertiary structure binding $\mathrm{Zn}^{2+}$ ions. In addition to the B-box motifs at the N-terminus, sometimes a CCT (CONSTANS, CO-like, TOC1) domain is present at the C-terminus (Khanna et al. 2009; Robson et al. 2001). The B-box motifs are composed of $\sim 40$ amino acids in length and are divided into two types, B-box1 and B-box2, based on their consensus sequence and the spacing of the zinc finger binding domain (Gangappa and Botto 2014). A total of $32 \mathrm{BBX}$ proteins have been identified in Arabidopsis thaliana (Khanna et al. 2009), which are simplified into five clusters (I-V) according to the presence or absence and topology of their B-box and CCT domains (Crocco and Botto 2013).

B-box proteins are likely to be involved in DNA binding, RNA binding or protein-protein interactions (Gangappa and Botto 2014). Functionally, BBX proteins have been linked to regulatory networks controlling plant development and growth, photoperiodic regulation, circadian rhythm and responses to biotic and abiotic stresses (Datta et al. 2007; Ding et al. 2018; Crocco and Botto 2013; Han et al. 2020; Kumagai et al. 2008; Xu et al. 2017; Zhang et al. 2017). In addition, recent analysis of gene expression profiles implies that BBX proteins are involved in plant hormone signalling including abscisic acid (ABA), brassinosterioids, gibberelling, cytokinin and auxin signals (Cao et al. 2019; Fan et al. 2012; Sánchez et al. 2004; Sun et al. 2010; Wang et al. 2013b; Huang et al. 2012). However, the role of B-box zinc finger TFs in plant stress is still poorly understood. In a review compiled by Gangappa and Botto (2014), 13 of the 32 Arabidopsis BBX genes were linked to an abiotic stress response, mostly cold and salt stress. The majority of these genes also responded to an ABA input signal leading to increased expression. Specifically, in relation to drought tolerance, the MdBBX10 gene from apple was upregulated under salt and osmotic stresses and when overexpressed in Arabidopsis enhanced drought tolerance by increasing the transgenic plants' ability to scavenge reactive oxygen species (Liu et al. 2019). The rice zinc finger protein, OsMSR 15 containing a B-box motif, enhanced drought tolerance in Arabidopsis. These transgenic plants had higher levels of proline, displayed less membrane damage and increased the expression of a number of stress response genes (Zhang et al. 2016).

$A t B B X 29$ is a B-box zinc finger protein, part of the BBX protein family in Arabidopsis thaliana. Since this protein has a single B-box domain, it falls within structure group $\mathrm{V}$ (Crocco and Botto 2013). It functions as a sequence-specific
DNA-binding transcription factor. Since it is a member of the CONSTANS gene family, putative functions such as flowering regulation have been assigned to this gene (Putterill et al. 1995). CmBBX29, a homologue isolated from chrysanthemum, has also been linked to the regulation of flowering when overexpressed in Arabidopsis (Chen et al. 2020). A study by Mikkelsen and Thomashow (2009) identified $A t B B X 29$, which they named CONSTANS-like (COL1), as being upregulated by low temperature in a $\mathrm{CBF}$ independent manner. Further investigations revealed an evening element (EE) motif (AATATCT), an MYB TF CCA1 binding site (AAAAATCT) and six ABA response element (ABRE)-like motifs, one of which was part of a G-box (CACGTG), in the promoter of this gene. The G-box has been implicated in a number of ABA-regulated gene expression pathways, which include the binding of bZIP TFs (basic region/leucine zipper motif) (Droge-Laser et al. 2018). Furthermore, the AtBBX29 TF is conceived to play a role in photosynthetic machinery and chloroplast redox conditions (Soitamo et al. 2008). Therefore, due to its perceived link with especially $\mathrm{ABA}$, the purpose of our study was to investigate if overexpression of $B B X 29$ from A. thaliana will provide improved tolerance to water-deficit stress in sugarcane. In selected transformed sugarcane plants, we particularly measured plant growth as well as physiological and biochemical activities after exposure to drought when compared with wild-type plants.

\section{Materials and Methods}

\section{Vector Construction}

The full-length $B B X 29$ transcription factor (TF) gene (accession number: At5g54470) was amplified from Arabidopsis thaliana Columbia ecotype (Col-0) cDNA using Q5 HighFidelity DNA Polymerase (New England Biolabs, Ipswich, USA) and forward (5'- GCAGGTCGACGGATCATGG GGSSGAAGAAGTGCGAGTT-3') and reverse (5' GAATTCCCGGGGATCTCAATAAAACGAAGACGACG ATGA-3') primers containing BamHI sites. The amplicon was cloned into the BamHI site of the pUbi510 vector to generate the recombinant plant expression vector, pUbi510:AtBBX29, which contains an ubiquitin promoter and cauliflower mosaic virus (CaMV) terminator. The recombinant vector was transformed using a standard heat-shock protocol into DH5 $\alpha$ Escherischia coli cells and sequenced.

\section{Genetic Transformation of Sugarcane}

Embryogenic callus was initiated from Saccharum spp. hybrid, cultivar NCo310 immature apical inner leave roll tissue and placed on MSC3 medium (4.43 g/L MS (Murashige and 
Skoog 1962) with vitamins), $20 \mathrm{~g} / \mathrm{L}$ sucrose, $0.5 \mathrm{~g} / \mathrm{L}$ casein, $3 \mathrm{mg} / \mathrm{L} 2,4 \mathrm{D}$ (2,4-dichlorophenoxyacetic acid) and $2.22 \mathrm{~g} / \mathrm{L}$ gelrite; $\mathrm{pH}$ 5.8). Cultures were incubated in the dark at $26^{\circ} \mathrm{C}$ and sub-cultured onto fresh media every 2 weeks. Prior to bombardment, as described by Bower and Birch (1992), embryogenic callus was placed on osmoticum medium (MSC3Osm), consisting of the basic MSC3 medium with the addition of $0.2 \mathrm{M}$ of each mannitol and sorbitol, at $26^{\circ} \mathrm{C}$ for $4 \mathrm{~h}$ in the dark.

A DNA precipitation mix was prepared containing $5 \mathrm{mg}$ sterilised tungsten (Grade M10: Biorad, \#165-2266), mixed with $5 \mu \mathrm{L}$ each of the pUBi510:AtBBX29 $(1 \mu \mathrm{g} / \mu \mathrm{L})$ and $\mathrm{pEmuKN}(1 \mu \mathrm{g} / \mu \mathrm{L}$; selection vector; Last et al. 1990) vectors, $50 \mu \mathrm{L} 2.5 \mathrm{M} \mathrm{CaCl}_{2}$ and $20 \mu \mathrm{L} 0.1 \mathrm{M}$ spermidine. The pEmuKN selection vector contained the neomycin phosphotransferaseII (nptII) gene as selection marker.

For bombardment, $5 \mu \mathrm{L}$ of the DNA precipitation mix was placed into the centre of a $1 \mathrm{~mm}^{2}$ metal grid above the target callus. Target tissue was placed $16.5 \mathrm{~cm}$ below the particle source and the helium bombardment pressure set at $1000 \mathrm{kPa}$. Biolistic particle delivery was done using a homemade system where the vacuum chamber was evacuated to reach $80 \mathrm{kPa}$ before the precipitation mix was discharged. Bombarded tissue was cultured on selection medium (MSC3) containing $45 \mathrm{mg} / \mathrm{L}$ geneticin for 8 weeks in the dark at $26^{\circ} \mathrm{C}$. Putative transformed calli were transferred to selection medium lacking 2,4-D and incubated at $26^{\circ} \mathrm{C}$ at a $16 / 8$-h light/dark photoperiod (50 $\mu \mathrm{mol}$ photons $\mathrm{m}^{-2} \mathrm{~s}^{-1}$ of luminosity) under cool white fluorescent lights (Osram, L 58 V/740) for somatic embryo formation. Regenerated plantlets were allowed to grow to a height of $\sim 5 \mathrm{~cm}$ and developed roots prior to transfer to the glasshouse.

\section{Molecular Analysis of Transgenic Sugarcane}

Leaf tissue was harvested from each putative transformed plantlet and non-transgenic WT sugarcane and grinded to a fine powder using liquid nitrogen. Genomic DNA was extracted using the ZR/Plant/Seed DNA MiniPep Kit (Zymo research, USA). Transgene integration was confirmed through standard PCR amplification using $200 \mathrm{ng}$ of genomic DNA as template in combination with gene-specific and ubiquitin promoter primer (UbiFor: 5'-ATACGCTATTTATTTGCTTGG$3^{\prime}$ ) pairs. Amplicons were separated and visualised through gel electrophoresis.

Total RNA was extracted from leaf tissue harvested from transgenic and WT plant lines and grinded to a fine powder using liquid nitrogen and the Maxwell®16 LEV Plant RNA Kit (Promega, Madison, USA). cDNA was synthesised from $1 \mu \mathrm{g}$ RNA using the Reverse Aid H minus First strand cDNA synthesis Kit (ThermoFisher Scientific, Waltham, USA) according to the manufacturer's protocol. Semi-quantitative RTPCR was performed using cDNA template to access relative levels of transgene expression. Transgene-specific forward (5'-CTAATTTTCTGGTGGCGAAACACATGCG-3') and reverse $\left(5^{\prime}\right.$ - CAATGGTCTAGAT TGGTTCTCCTCCTG CATTTC- $3^{\prime}$ ) primers and primers designated for the actin gene (5'-TCACACTTTCTACAATGAGCT-3' and 5'GATATCCACATC ACACTTCAT-3') used as internal reference gene were used in combination with GoTaq DNA polymerase in standard PCRs and visualised through gel electrophoresis.

\section{Analysis of Plant Growth under Normal Environmental Conditions}

To observe the phenotypes of plants under normal conditions, harden off transgenic and wild-type sugarcane plants were transferred and grown in big $56 \mathrm{~cm}$ pots containing a $2: 1$ mix of potting soil and sand in a growth tunnel under natural light and temperature. The plants were regularly watered, received fertiliser during the watering regime, and were allowed to grow for 8 months. Agronomic growth measurements of plant height, leaf width, leaf length and internodes lengths were taken from 3 stalks of each of the four (4) biological repeats for each transgenic and wild-type (WT) line. Plant height was measured from the soil level to the top visible dewlap leaf (TVD). The TVD is the first leaf from the top of the plant that has a visible dewlab formed on the stalk. The TVD was also used as a measuring point for the leaf width, which was recorded $10 \mathrm{~cm}$ away from the dewlap following the length of the leaf. The internode length was measured for internodes 7,8 and 9; internodes were counted from the top to the bottom of the stalk, youngest to oldest, respectively.

To determine the carbohydrate content, mature (internode 9) and immature (internode 3) internode tissues were harvested from the 8 months old transgenic and WT sugarcane plants. Total soluble carbohydrates were extracted from $20 \mathrm{mg}$ grinded frozen internode tissue using the ethanol extraction method described by Chow and Landhäusser (2004). Sugar levels were measured using the BOEHRINGER MANNHEM/R-BIOPHARM Enzymatic BioAnalysis/Food Analysis kit (R-Bopharm, Boehringer Manheim, Darmstadt, Germany) following the manufacturer's instructions. Absorbance was measured at a wavelength of $340 \mathrm{~nm}$ using a VesrsaMax ELISA Microplate reader and the sucrose, glucose and fructose concentrations were expressed as $\mu \mathrm{mol} / \mathrm{g} \mathrm{FW}$.

\section{Analysis of Transgenic Sugarcane Plants under Drought Conditions}

Three transgenic lines and WT sugarcane were multiplied in vitro on half strength MS ( $1 / 2 \mathrm{MS})$ medium containing $2 \%$ sucrose, $2 \mathrm{mg} / \mathrm{L}$ 1-naphthalene-acetic acid (NAA)) and $0.22 \mathrm{~g} /$ $\mathrm{L}$ gelrite; $\mathrm{pH}$ 5.8. Twenty five rooted in vitro plantlets per 
genotype were harden off in the glasshouse by planting in $20 \mathrm{~cm}$ pots containing a homogenous mixture of soil consisting of $2: 1: 1$ palm peat:sand:vermiculite and placed in the glasshouse at $26 \pm 2{ }^{\circ} \mathrm{C}$. Plants were watered every two days and fertilised with $3 \mathrm{~g} / \mathrm{L}$ Hydrotech Generic Fertiliser (Hydrotech, Stellenbosch, SA) and $2.5 \mathrm{~g} / \mathrm{L}$ calcium nitrate $\left[\left(\mathrm{Ca}_{2}\left(\mathrm{NO}_{3}\right)^{2}\right]\right.$ every two weeks.

Four-month-old healthy plants in the tillering stage of development were deprived of water and subjected to drought for 21 days. The soil surface of each pot included in the trial was covered with a plastic disc to ensure slow drying of the soil. The soil moisture content of all pots were measured every second day using the ProCheck (Decan Devices, Washington, USA) probe inserted $9 \mathrm{~cm}$ deep into the soil and recorded three readings per pot around the plant stem. Once water was withheld, physiological measurements were taken every second day using the top visible dew lap leaf (TVD) as the measuring point. Plant growth was recorded by measuring the plant height and length and width of the TVD of the transgenic and WT plants included in the trial. Measurements were recorded every 7 days on days $0,7,14$ and 21 without water (ww). In addition, on the same days, leaf material above and below the TVD were harvested, flash frozen in liquid nitrogen and stored at $-80^{\circ} \mathrm{C}$ for further biochemical analysis.

\section{Physiological Analysis of Plants Exposed to Drought}

Leaf discs from transgenic and WT plants were cut from the TVD and fresh weights (FW) recorded immediately. The leaf discs were then floated on distilled water at room temperature overnight and the full turgid weight (TW) recorded. The leaf discs were then dried at $80{ }^{\circ} \mathrm{C}$ for 2 days and the dry weight (DW) recorded. According to Smart and Bingham (1974), RWC was calculated as a percentage using the formula: RWC $\%=[(\mathrm{FW}-\mathrm{DW}) /$ $(\mathrm{TW}-\mathrm{DW})] \times 100$.

Stomatal conductance and chlorophyll fluorescence were measured at three surface positions on the TVD of four plants per genotype using a Decan Leaf Porometer SC-1 (Decagon Devices, Pullman, USA) and OS-30p + (OPTI-SCIENCES, Hudson, USA) fluorometer, respectively. Measurements were taken every two days, starting with non-stress plants on day 0 of the trial. Clip shutters were applied twenty minutes prior to recording chlorophyll fluorescence.

Total chlorophyll in the sugarcane leaves was extracted from $100 \mathrm{mg}$ material using $80 \%(\mathrm{v} / \mathrm{v})$ acetone according to the method described by Hiscox and Israelstam (1979). The extraction procedure was repeated three times, and all collected supernatant phases were combined and the absorbance measured at wavelengths 663 and $645 \mathrm{~nm}$ according to Arnon (1949). Total chlorophyll content was calculated using the formula: $\mu \mathrm{g} / \mathrm{mL}=20.2\left(\mathrm{~A}_{645}\right)+80.2\left(\mathrm{~A}_{663}\right)$.

\section{Electrolyte Leakage and Lipid Peroxidation}

The electrolyte conductivity (EC) in the TVD leaf cells was measured using the AD31 waterproof pocket EC/TDS temp probe (Adwa Instruments, Szeged, Hungary), according to the method described by Valentovic et al. (2006). Harvested tissue was immersed in deionised water for $24 \mathrm{~h}$ and the $\mathrm{EC}$ of the solution recorded $\left(\mathrm{EC}_{1}\right)$. The tissues were then frozen in liquid nitrogen, placed back into deionised water and disintegrated by vortexing and the $\mathrm{EC}\left(\mathrm{EC}_{2}\right)$ measured. Electrolyte leakage (EL) was calculated as: $\%=\left[\left(\mathrm{EC}_{1}\right) /\right.$ $\left.\left(\mathrm{EC}_{2}\right)\right] \times 100$.

Lipid peroxidation was determined by measuring the malondialdehyde (MDA) content following the method of Heath and Packer (1968) where the absorbance of the prepared extracts was measured at $532 \mathrm{~nm}$ and $600 \mathrm{~nm}$. Leaf samples were grinded and extracted in $6 \%$ trichloroacetic acid (TCA) and subsequently reacted with $0.5 \%$ thiobarbituric acid (TBA), boiled at $95{ }^{\circ} \mathrm{C}$ for $30 \mathrm{~min}$, centrifuged and cooled before the absorbance was read. MDA concentrations were calculated using the extinction coefficient of $155 \mathrm{mM} \mathrm{cm}^{-1}$.

\section{Measurement of ROS, Antioxidants, Proline and ABA Accumulation}

In situ detection of hydrogen peroxide $\left(\mathrm{H}_{2} \mathrm{O}_{2}\right)$ was conducted according to the method described by Daudi and O'Brien (2012) using 3,3-diaminobenzidine (DAB) staining (1 mg/ $\mathrm{mL}$ in $10 \mathrm{mM}$ phosphate buffer; $\mathrm{pH}$ 3.8). Superoxide radicals $\left(\mathrm{O}_{2}{ }^{-}\right)$were detected using nitroblue tetrazolium (NBT) staining (3 mg/mL in $10 \mathrm{mM}$ phosphate buffer; $\mathrm{pH} 7.8$ ) according to a method described by Kumar et al. (2014). The TVD of transgenic sugarcane lines and WT sugarcane was used as a test material. Chlorophyll was removed by de-staining the leaf discs in $96 \%$ ethanol at $60{ }^{\circ} \mathrm{C}$ for both DAB and NBT histochemical staining experiments. In addition, $\mathrm{H}_{2} \mathrm{O}_{2}$ was quantified by homogenising $100 \mathrm{mg}$ of grinded leaf tissue in $0.1 \%$ TCA followed by centrifugation (Junglee et al. 2014). Whilst working in the dark, the supernatant was collected and mixed in $1: 2$ ratio with $5 \mathrm{mM}$ potassium phosphate buffer $(\mathrm{pH} 7)$ and $1 \mathrm{M}$ potassium iodide (KI). The absorbance was measured at $390 \mathrm{~nm}$.

For the measurement of anti-oxidase enzyme activity, $100 \mathrm{mg}$ of grinded plant leaf tissue was homogenised in extraction buffer $\left(0.1 \mathrm{M} \mathrm{K}_{2} \mathrm{HPO}_{4}, 0.1 \mathrm{mM}\right.$ EDTA, and $1 \%(\mathrm{w} / \mathrm{v})$ polyvinylpyrrolidone [PVP]; $\mathrm{pH} 7$ ). The total protein content of the extracts was quantified using a standard Bradford Assay (Bradford 1976). All assays were conducted using four biological repeats of transgenic and WT sugarcane plants and readings were measured in triplicate.

CAT activity was determined using the Catalase Kit (Sigma-Aldrich, Saint Louis, USA), according to the manual specifications and the activity determined 
spectrophotometrically by measuring the quinoneimine dye formation at $520 \mathrm{~nm}$. SOD activity was determined using the SOD Assay Kit (Sigma-Aldrich, Saint Louis, USA), according to the manufacturer's guidelines at $450 \mathrm{~nm}$. SOD was expressed as inhibition rate preventing oxidation of watersoluble tetrazolium salt (WST) from forming formazan.

Glutathione activity in stress and unstressed transgenic and WT plants were measured per the protocol of Sahoo et al. (2017), as total oxidised glutathione (GSSG) and reduced glutathione $(\mathrm{GSH})$. Plant extracts were prepared by homogenising $200 \mathrm{mg}$ of grinded leaf tissue in $6 \%$ metaphosphoric acid containing $1 \mathrm{mM}$ EDTA and $0.5 \mathrm{M}$ potassium phosphate buffer ( $\mathrm{pH}$ 7.5). Following the initiation of the enzyme reaction, reduced glutathione was measured at $412 \mathrm{~nm}$. GSSG was measured after the addition of 2vinylpyridine to the prepared extracts and enzyme activation at $412 \mathrm{~nm}$ for $5 \mathrm{~min}$ and $15 \mathrm{~s}$ intervals.

The proline content in leaf tissue from the different genotypes under water-deficit stress was determined by homogenising $50 \mathrm{mg}$ of grinded material in $3 \%$ sulfosalicyclic acid following Bates et al. (1973). Proline concentrations were measured at an absorbance of $520 \mathrm{~nm}$.

Abscisic acid (ABA) was extracted by lyophilizing $400 \mathrm{mg}$ leaf tissue harvested from the different plant types under stress and unstressed conditions. The dried material was homogenised in $80 \%$ methanol as per Liu et al. (2014). The ABA content of the extracts was quantified using the Phytodetek ABA test kit (Agdia, Indiana, USA) according to the manufacturer's specification.

\section{Statistical Analysis}

All measurements were taken from four biological repeats $(n=4)$ with measurements done in triplicate. The data was presented as the mean \pm standard deviation (SD) and subjected to one-way ANOVA for analysis of variance and significance in responses of transgenic lines against WT at $p$ values $\leq 0.05$ $(*), \leq 0.01(* *)$ or $\leq 0.001(* * *)$ followed by Benferroni's or Tukey's multiple comparison tests. Analysis was done with Graphpad Prism software version 5.0 (Motulsky 2014).

\section{Results}

\section{Cloning and Sequence Analysis of AtBBX29}

The full-length cDNA sequence of AtBBX29 (TAIR accession number: AT5g54470) was amplified from Arabidopsis thaliana. The open reading frame of AtBBX29 is $648 \mathrm{bp}$ in length and encodes for 216 amino acid residues. Only one Bbox motif is present at amino acid residue coordinates 6 to 42 , with two pairs of cysteine and histidine residues present, showing the typical, mostly conserved residues found in all
B-box 1 motifs seen in structural group $\mathrm{V}$ of the BBX protein family of Arabidopsis (Fig. 2a). The transgene was cloned into the pUbi510 plant expression vector to generate pUbi510:AtBBX29 (Fig. 2b).

\section{Molecular Confirmation of Putative Transgenic Sugarcane Plants}

Sugarcane embryogenic calli were regenerated and bombarded with the pUbi510:AtBBX29 vector (Fig. 1) and, at the end of the transformation experiment, five putative transformed clones were regenerated via somatic embryogenesis. The transgenic sugarcane plants were confirmed by polymerase chain reaction (PCR) amplification of the AtBBX29 gene (Fig. 2c) and lines T1.1, T1.6 and T1.8 were selected for functional validation. Semi-quantitative reverse transcription (RT)-PCR confirmed expression of the $A t B B X 29$ gene in the transgenic sugarcane, while no expression was detected in the wild-type (WT) plants. Two transgenic lines, T1.1 and T1.6, showed relatively low transgene transcript levels, while transgenic line T1.8 had relatively high AtBBX29 transcript levels. The internal control actin transcripts were present in all the plants (Fig. 2d).

\section{Growth Performance of Transgenic Plants Under Normal Irrigation}

The growth responses of the WT and transformed plants overexpressing AtBBX29 were assessed after eight months of growth under normal environmental conditions with a consistent watering regime (Supplementary Fig. S1). All the transgenic plants had comparable morphologies with the WT plants, with no significant difference in the internode length or plant height. Only leaf length and width differ significantly in transgenic lines T1.8 and T1.1, respectively, when compared to the WT plants (Supplementary Fig. S1).

Sucrose content in the immature (I 3) and mature (I 9) internodes of the AtBBX29 transgenic and WT plants was the same. As expected, sucrose was much higher in the mature versus immature internodes (Fig. 3a). Glucose and fructose levels were similar in immature cane tissue in all the genotypes. Variation and significant lower levels of glucose and fructose were seen in I 9 in some of the transgenic lines (T1.1 and T1.8) compared to WT (Figs. 3b and c).

\section{Phenotypic Response of WT and Transgenic Sugarcane Exposed to Drought}

Four-month-old AtBBX29 transgenic sugarcane, lines T1.1, T1.6 and T1.8, and WT plants were exposed to 21 days of water-deficit stress, after which the plants were rewatered (Fig. 4). The relative water content (RWC) of all the plants decreased during the drought treatment, consistent with the 

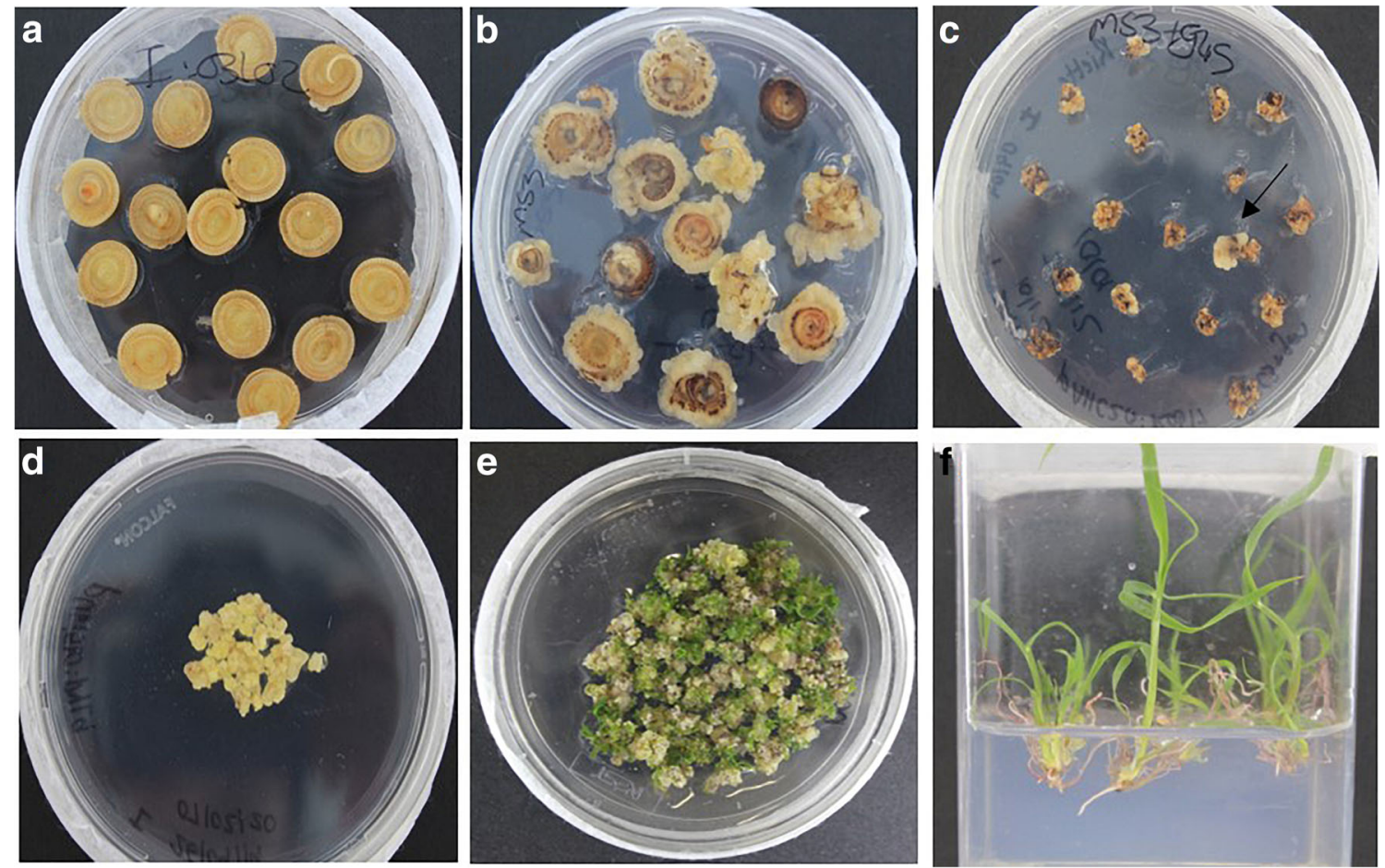

Fig. 1 Generating in vitro putative transformed sugarcane (Saccharum spp. hybrid cv. NCo310) plantlets from bombarded embryogenic callus. Callus was initiated from a immature inner leaf roll explants isolated from stalk material, followed by the $\mathbf{b}$ regeneration of callus prior to transformation. c Bombarded callus was placed on selection media, and surviving calli (indicated by arrow) were allowed to $\mathbf{d}$ multiply and $\mathbf{e}$ form somatic embryos, which developed into f sugarcane plantlets with roots massive drop in soil moisture content in the pots. However, most of the transgenic plants maintained a significantly higher RWC during the drought treatment, especially towards the end of the stress period, than the WT plants (Fig. 5). Plant growth was similar in all the genotypes during the drought period (Supplementary Table SI). However, the WT plants started to exhibit stress symptoms without water (ww) by day 14 , where $6 \%$ of the plants died and $47 \%$ of the plants started to display stress-induced damage, such as the chlorosis of leaf tips and leaf curling and wilting. In contrast, between 77 and $83 \%$ of the transgenic plants showed no signs of stress, with only 17 to $23 \%$ of the plants showing minimal damage, such as leaf tip yellowing.

Extended drought (21 days ww) increased WT plant death to $63 \%$ (Fig. 5c), whereas most of the transgenic lines survived longer (T1.1 and T1.6 between 40 and $50 \%$ ) and remained healthy. By day $21 \mathrm{ww}$, leaf length was reduced by an average of $12 \mathrm{~cm}$, while the transgenic lines remained mostly unaffected. The same response was observed in the values obtained for plant height where the transgenic plants tended to be higher than the WT plants but not at significant levels due to the increased variations seen among individual plants within a genotype (Supplementary Table S1).

When rewatered, $20 \%$ of the transgenic and $4 \%$ of the WT plants recovered and formed new green leaves
(Fig. 4). The adaptive responses of plants to drought can be ABA-dependent or ABA-independent. ABA levels were measured in the leaves of the transgenic and the WT plants during the dry period. No significant difference was detected in ABA content between the transgenic and the WT plants under normal environmental conditions or under drought conditions (data not shown).

\section{AtBBX29 Involved in the Protection of Photosynthetic Machinery Under Drought Stress}

The role of $A t B B X 29$ in maintaining the photosynthetic capacity of the plants during the 21 days of drought was investigated by measuring chlorophyll fluorescence (Fv/ Fm), stomatal conductance and chlorophyll content (Fig. 6). No significant differences were found for these parameters under non-stress conditions. However, chlorophyll fluorescence was higher in the transgenic plants, with lines T1.8 and T1.1 significantly higher, under mild drought stress conditions (5 days ww) than in the WT plants. Under extended severe drought stress conditions (21 days ww) all the transgenic lines maintained a high photosynthetic rate, significantly higher in T1.8 and T1.1, than the WT plants. From the 10th day of stress, the stomatal conductance of the WT plants was significantly reduced compared to the levels in all the 
(a)
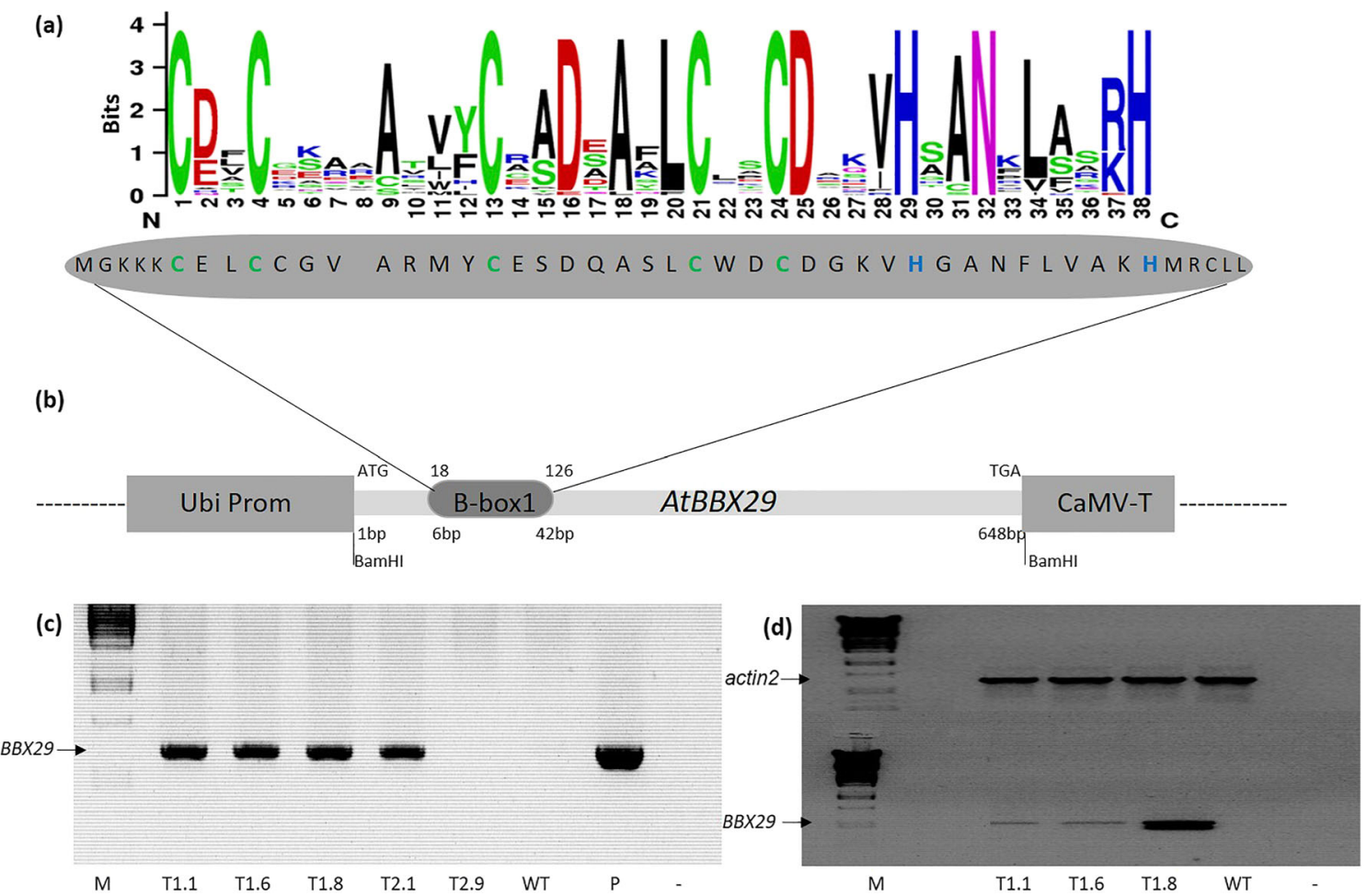

Fig. 2 Sequence of $A t B B X 29$. a The highly conserved sequence of the Bbox domain present in $A t B B X 29$ aligned with the distinct B-box 1 motif in the Arabidopsis B-box family of proteins. Conserved residues across all Arabidopsis proteins are indicated by letter height for each amino acid, with a bit score of 4 as described by Khanna et al. (2009). b The AtBBX29 gene cloned into the pUbi510 plant expression vector containing an ubiquitin promoter and CaMV terminator. Furthermore, PCR confirmation of

transgenic lines. Chlorophyll content in the WT and transgenics declined as the drought period was extended transgenic sugarcane by $B B X 29$ gene amplification. $\mathbf{c}$ The transgene was present in four of the putative transformed sugarcane lines (T1.1, T1.6, T1.8 and T2.1); d semi-qualitative RT-PCR confirmation of transgene expression in transgenic lines T1.1, T1.6 and T1.8 using actin as an internal control. $M$ is a PstI $\lambda$ marker, $W T$ the wild-type negative control, $P$ the positive plasmid control, and - the negative $\mathrm{H}_{2} \mathrm{O}$ control

but the levels were not significantly different between the genotypes.
Fig. 3 The levels of total soluble sugars in the immature and matured internodes (I 3 and I 9) of AtBBX29 transgenic sugarcane (T1.1, T1.6 and T1.8) and WT plants measured after 8 months of growth under normal environmental conditions.

Measurements include a sucrose, b glucose and $\mathbf{c}$ fructose content. Data is presented as means \pm SD of nine biological replicate (three stalks each from 3 plants; $n=9$ ). The asterisks indicated $\left({ }^{*}\right)$ and $\left(^{* *}\right)$ significant difference between the transgenic and WT plants at $p \leq$ 0.05 and $p \leq 0.01$ (a)

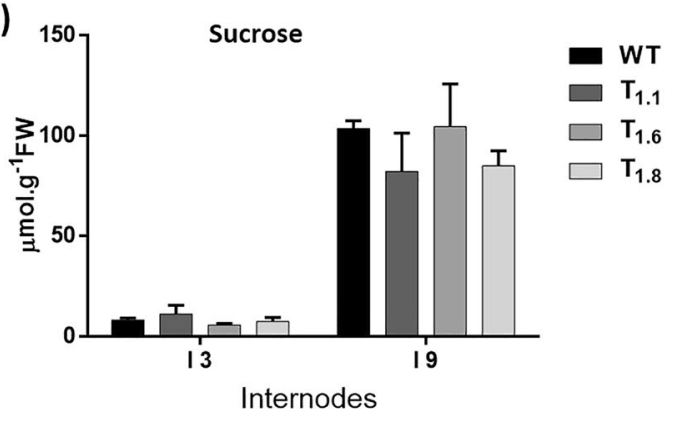

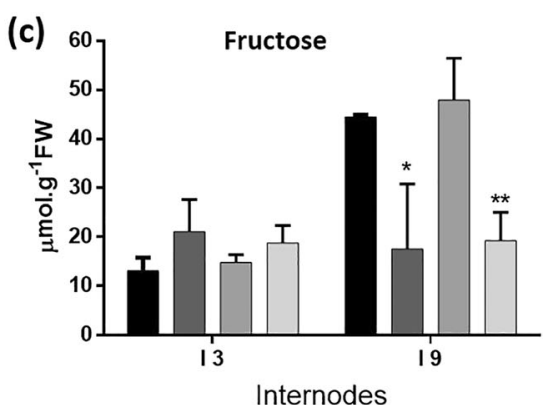



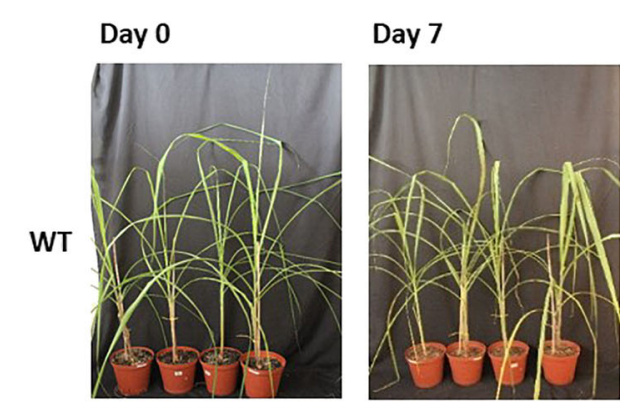

\section{Day 14}
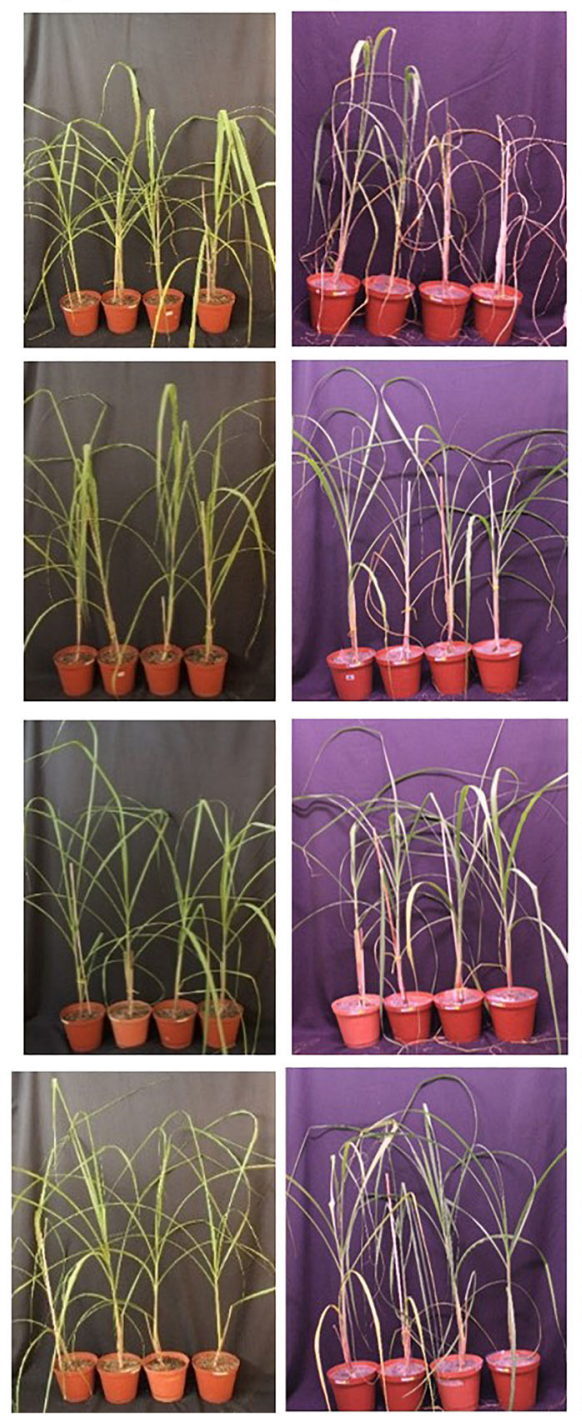

Day 21
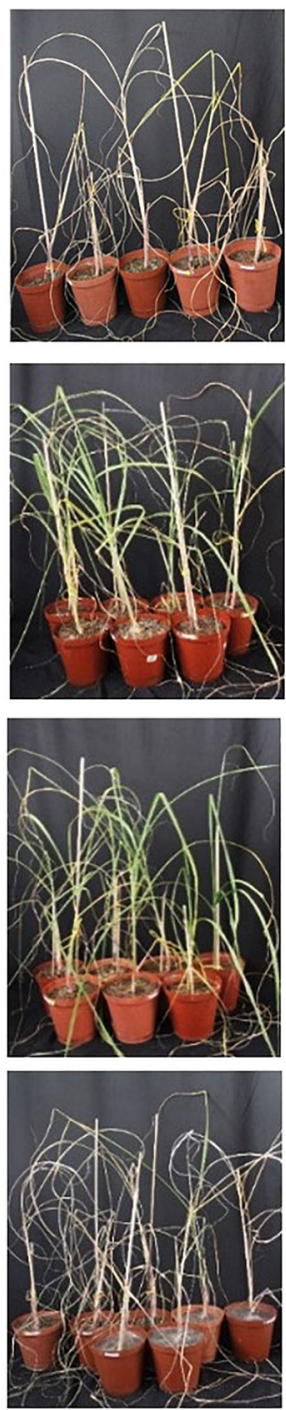

Recovery
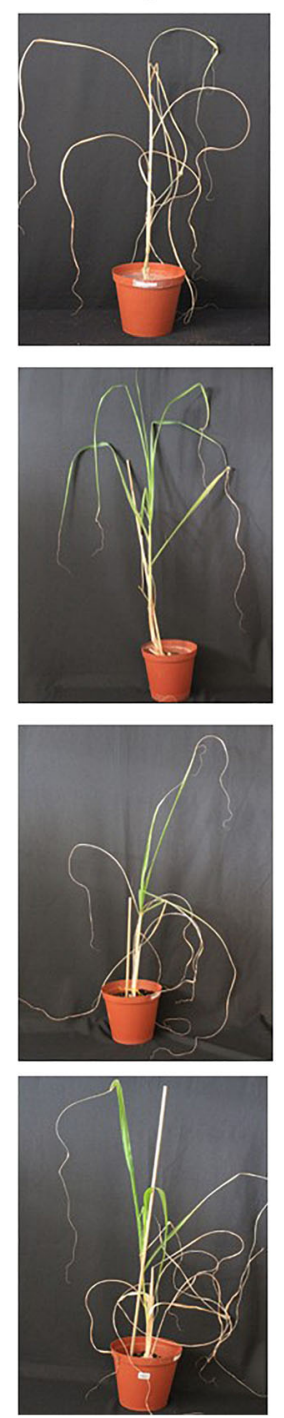

Fig. 4 A sample representation of the phenotypic variation of $A t B B X 29$ transgenic sugarcane lines (T1.1, T1.6 and T1.8) and WT plants under drought. Drought was initiated by deprivation of water for a period of
21 days. Phenotypic analysis was evaluated every 7 days of water deprivation and recovery after 14 days of rewatering

\section{AtBBX29 Overexpression Alleviating Drought- Induced Oxidative Stress by Improving Antioxidant Capacity}

Abiotic stress leads to the accumulation of reactive oxygen species (ROS), which plants scavenge through an enhanced antioxidant defence system. All the WT and transgenic plants showed a low production of ROS, indicated by a weak staining of both diaminobenzidine (DAB) and nitroblue tetrazolium (NBT), and low quantified $\mathrm{H}_{2} \mathrm{O}_{2}$ values under nonstressed conditions ( 0 days ww). As the drought period continued, the transgenic lines exhibited a slightly lower accumulation of $\mathrm{O}_{2}{ }^{-}$and $\mathrm{H}_{2} \mathrm{O}_{2}$ than the WT sugarcane plants, which displayed some increase in dark brown and blue staining streaks outside the midrib area of the leaf structure (Figs. $7 \mathrm{a}$ and c). However, the staining patterns were difficult to interpret and $\mathrm{H}_{2} \mathrm{O}_{2}$ was therefore quantified; significantly lower levels of $\mathrm{H}_{2} \mathrm{O}_{2}$ were detected in most of the transgenic plants compared to the WT plants under mild and under severe water-deficit stress conditions (Fig. 7b).

Oxidative damage was predicted by measuring the final products of lipid peroxidation in the transgenic and WT plants exposed to water-deficit stress. In addition, electrolyte leakage (EL) was measured to reflect membrane permeability. Malondialdehyde (MDA) content was significantly lower in the transgenic plants under severe dry conditions (21 days ww) (Fig. 7d). The EL levels stayed the same in all the genotypes across the water-deficit stress period (Fig. 7e).

In defence against ROS, plants generate antioxidants, which comprise enzymatic and non-enzymatic activities. 


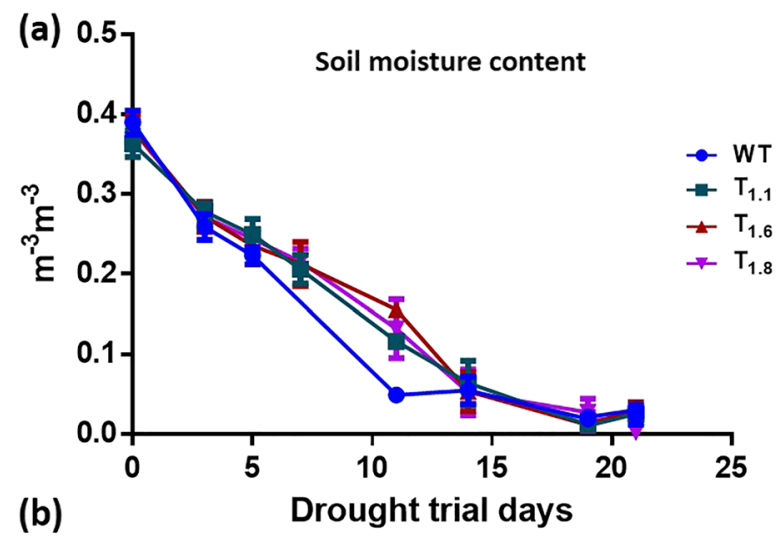

(b)

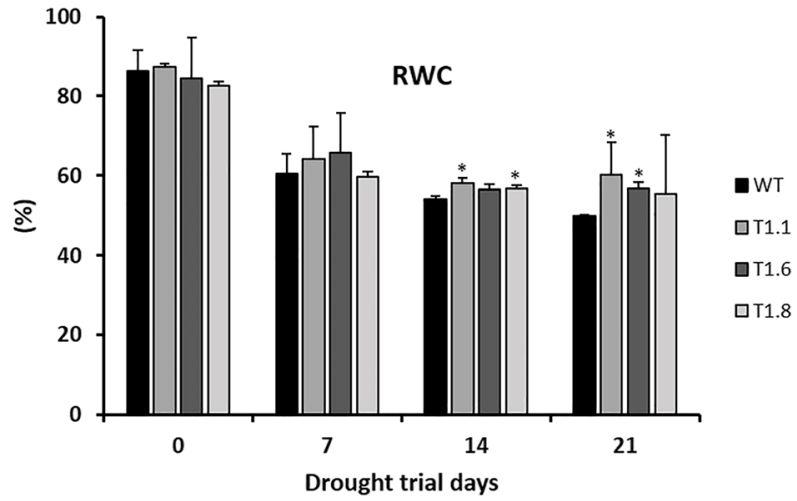

Fig. 5 Comparative analysis of a soil moisture content of all pots and $\mathbf{b}$ relative water content $(\%)$ in the leaves of transgenic sugarcane (T1.1, T1.6 and T1.8) and WT plants prior to and after induction of water-deficit stress. Data is presented as means $\pm \mathrm{SD}$ of four biological repeates $(n=4)$. The asterisks indicated significant difference between the transgenic and

The activity of the enzymatic antioxidants, superoxide dismutase (SOD) and catalase (CAT), was significantly higher in the transgenic plants than in the WT plants under severe drought stress conditions (Figs. 8a and b). The ratio of reduced glutathione (GSH) and oxidised glutathione (GSSG) accumulation is a measure of oxidative stress. Reduced glutathione increased during the dry period in all the plants but not at significantly different levels in the transgenic and WT plants (Fig. 8d). The GSSG levels of the overexpression lines were slightly higher than in the WT plants under normal conditions. The GSSG levels decrease in transgenic plants, with T1.8 at significantly lower levels from the WT. The GSSG levels stayed constant in the WT plants under mild water-deficit stress conditions (up to 14 days ww).

Proline is known to act as a compatible osmolyte and an ROS scavenger to counteract water-deficit stress. The transgenic and WT plants had similar low levels of proline under non-stress conditions (Fig. 8c). These levels remained low under mild stress (7 days ww) in all the genotypes but, by day $14 \mathrm{ww}$, the proline levels increased significantly in transgenic lines T1.1 and T1.8 compared to the WT plants. Under severe stress ( 21 days ww), all the transgenic plants had significantly higher levels of proline. (c)

\begin{tabular}{lccc} 
Plant line & Dead (\%) & Damaged (\%) & Healthy (\%) \\
\hline Day 14 & & & \\
WT & 6 & 47 & 47 \\
T1.1 & 0 & 21 & 79 \\
T1.6 & 0 & 17 & 83 \\
T1.8 & 0 & 23 & 77 \\
\hline Day 21 & & & \\
WT & 63 & & 37 \\
T1.1 & 60 & & 40 \\
T1.6 & 50 & & 50 \\
T1.8 & 73 & & 27 \\
\hline
\end{tabular}

WT plants at $p \leq 0.05$. c Survival rates (\%) based on morphological appearance in terms of leaf chlorosis, wilting and dry brittle leaf tissue. For each genotype, a total of 25 healthy plants were included in the pot trial. Each value represents the number of plants counted at a specific time point and expressed as a percentage

\section{Discussion}

In sugarcane, water-deficit stress impairs stalk and leaf growth, reduces leaf area, causes leaf rolling and senescence and influences photosynthesis (reviewed by Ferreira et al. 2017). Since mechanisms to escape drought are not possible in this perennial crop, sugarcane must either avoid dehydration through sustaining high water status, mostly by reduced stomatal conductance, or tolerate dehydration through mechanisms necessary to maintain plant function, such as osmotic adjustment (Blum 2005). What happens in the case of sugarcane is that it uses the $\mathrm{C} 4$ photosynthetic pathway that dominates most grass species in tropical and subtropical regions. It decreases stomatal conductance and the transpiration and photosynthetic rate, mostly due to stomatal limitations under mild water-deficit conditions and, under severe dehydration, uses avoidance adaptations, which reduce biomass accumulation, while tolerance mechanisms allow growth maintenance during stress conditions (Inman-Bamber and Smith 2005). In this study, we characterised the in planta physiological and biochemical responses of transgenic sugarcane lines overexpressing $A t B B X 29$ during irrigation and induced water-deficit stress. 

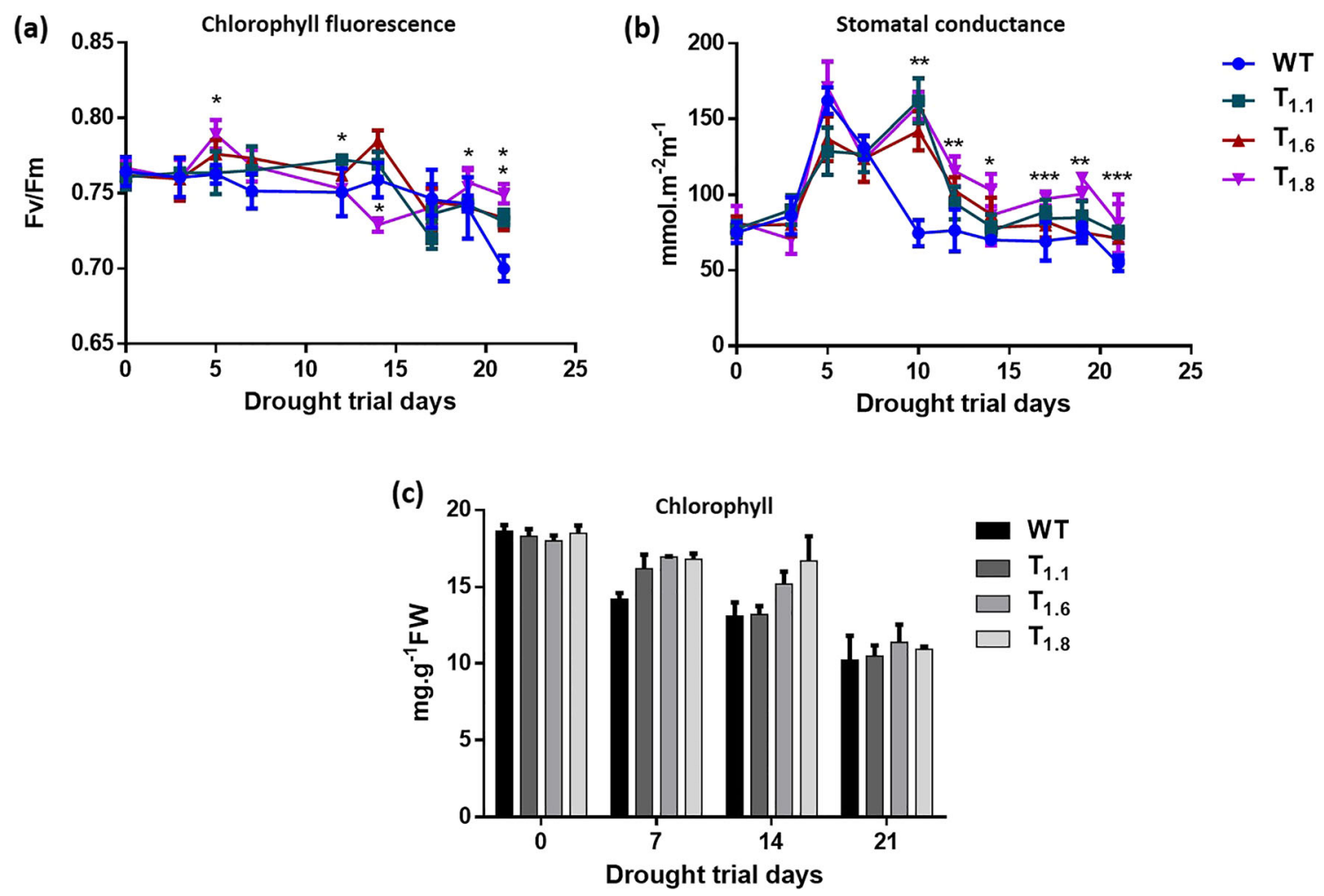

Fig. 6 Analysis of photosynthetic machinery of transgenic sugarcane (T1.1, T1.6 and T1.8) and WT plants prior to (day 0) and after exposure to water-deficit stress (7, 14 and 21 days ww). Measurements include the a chlorophyll fluorescence $(F v / F m)$, b stomatal conductance

BBX29 is a C2H2-type zinc finger protein classified according to its conserved cysteine and histidine residues and it contains one single B-box domain. When overexpressed in sugarcane, it did not change the phenotype of the mature sugarcane plants, the plants growing normally and accumulating sucrose in the stalks at levels similar to the WT plants. The overexpression of $A t B B X 29$, however, reduced the levels of glucose and fructose in the mature stalks. In sugarcane, sucrose is produced through photosynthesis in the leaves of the plant and then transported to the stem via the phloem. There, it can be either stored in the stem or converted into glucose and fructose, which are utilised to provide energy required for growth. Growth reduces the sucrose in the stem but allows the plant to increase both its sucrose production and its storage (Wang et al. 2013a). The overexpression of AtBBX29 might therefore decrease the conversion from sucrose into the monosaccharides, fructose and glucose. The transgenic plants, in contrast to the WT plants that operated in reduced $\mathrm{CO}_{2}$ fixating conditions, seemingly compensated for the balances found among sucrose used for growth and therefore the formation of glucose and fructose, sucrose production and sucrose storage. Alternatively, in the transgenic plants during the maturation phase, left-over glucose and fructose were converted more quickly into sucrose, again for storage, hence the lower monosaccharide concentrations. and $\mathbf{c}$ chlorophyll content of the different plants. Data is presented as means $\pm \mathrm{SD}$ of four biological replicates $(n=4)$. The asterisks $(*),(* *)$ and $(* * *)$ indicate significant differences compared to the WT at $p \leq 0.05$, 0.01 and 0.001 , respectively

The overexpression of $A t B B X 29$ provided better tolerance to drought by delaying the onset of leaf senescence, indicated by leaf tip yellowing and leaf rolling and wilting in the untransformed plants, retention of photosynthetic capabilities under mild and severe dehydration stress and overall better survival rates. The transgenic plants overexpressing $A t B B X 29$ in the tillering phase of growth (when they were four months old) maintained shoot height and leaf length during dehydration and also recovered better from the stress compared to the WT plants (a 20\% transgenic versus $4 \% \mathrm{WT}$ recovery rate). Although water-deficit stress significantly decreased the RWC in the WT plants (36\%), such severe decrease was not found in the transformed plants ( $27 \%$ average decrease across lines). Relative water content usually serves as a crucial indicator of how plants manage dehydration conditions, which are directly linked to soil moisture content (Hammad and Ali 2014). The transgenic plants, despite a huge decline in soil moisture content to almost completely dry soil, maintained a high RWC. The function of BBX proteins in abiotic stresses is still poorly understood. To date, in the Poaceae species, the $O s B B X 1, O s B B X 2, O s B B X 8, O s B B X 19$ and $O s B B 24$ genes have been linked to abiotic stress responses, including drought, through changes in their expression profiles, which potentially signify roles in the plants' stress response (Shalmani et al. 2019). In addition, a few BBX genes have been functionally annotated with regard to drought stress. The overexpression of 

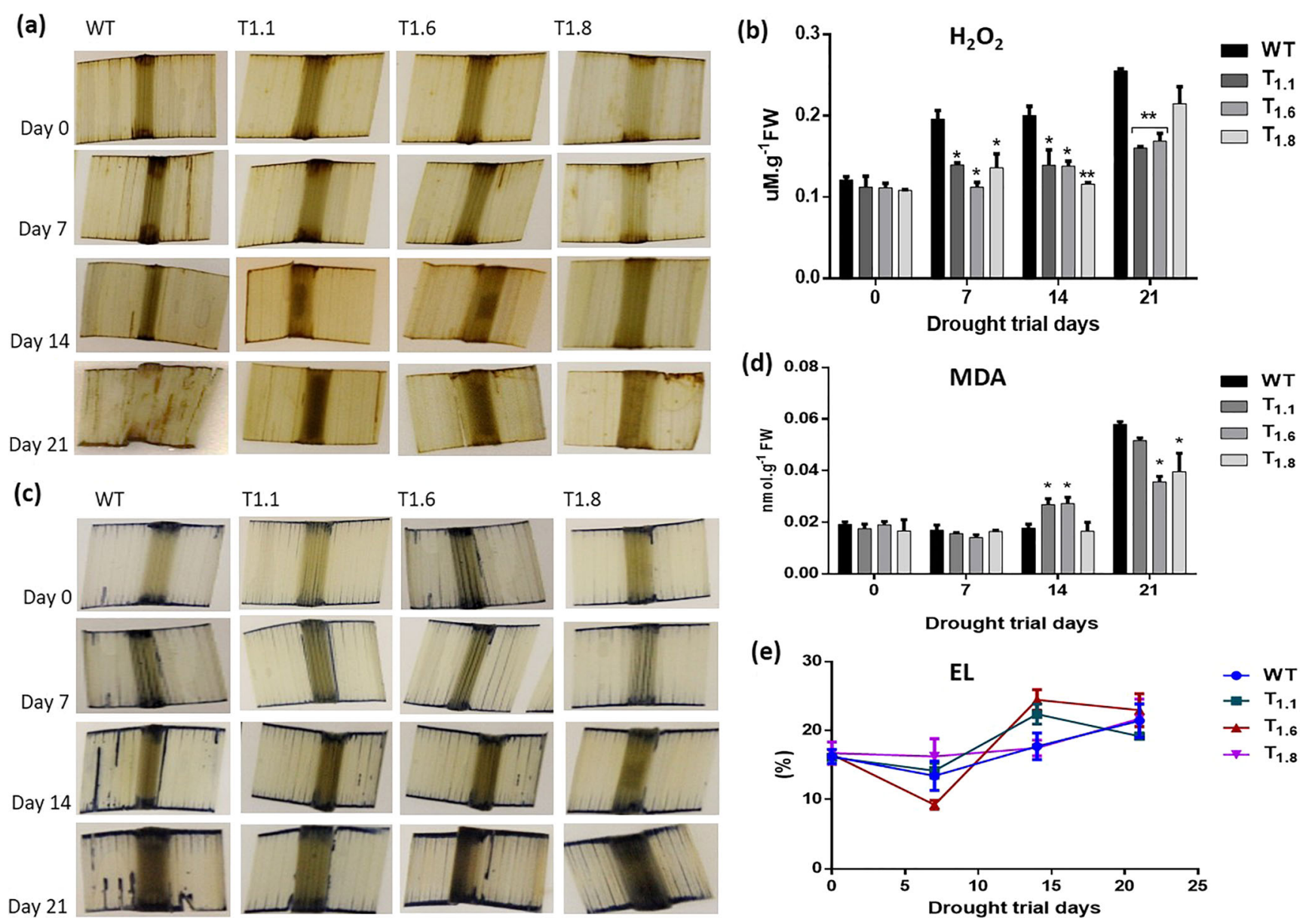

Fig. 7 Assessment of physiological characteristics involved in oxidative damage in transgenic and WT plants under control and drought stress conditions. In vivo detection of $\mathbf{a} \mathrm{H}_{2} \mathrm{O}_{2}$ and $\mathbf{c} \mathrm{O}_{2}{ }^{-}$and accumulation of b $\mathrm{H}_{2} \mathrm{O}_{2}$, d malondialdehyde (MDA) and e electrolyte leakage in the leaves of transgenic (T1.1, T1.6 and T1.8) and WT plants under water-

deficit stress, on days 0 to 21 without water. Data is presented as means \pm $\mathrm{SD}$ of three biological replicates $(n=3)$. Astrisks $(*),(* *)$ indicates significant difference between transgenic and WT plants at $p \leq 0.05$ and $p \leq$ 0.01

ZFP genes, namely ZFP179, 182, 245, 252 and 36, regulated drought tolerance in transgenic rice through oxidative and antioxidant defence in an ABA-dependant manner (Sun et al. 2010; Zhang et al. 2012, 2014). In dicotyledonous plant species, two BBX genes from Arabidopsis, BBX5 and BBX24 (also called $A t C O L 4$ and $S T O$ ), have been linked to osmotic stress tolerance, also through the ABA-dependant signalling pathway (Min et al. 2015; Nagaoka and Takano 2003). The overexpression of $M d B B X 10$ from apple enhanced drought stress tolerance in transgenic Arabidopsis by enhancing the plants' ability to scavenge reactive oxygen species (Liu et al. 2019). Similarly, in the promoter regions of the tomato genes $S I B B X 7$ and SIBBX12, ABA responsive elements were identified, which most likely also indicated a link to drought responses (Chu et al. 2016).

In the current study, we further found that the overexpression of $A t B B X 29$ had beneficial consequences for survival through changes in the photosynthetic performance of the plants following drought induction. Changes in photosynthetic performance during dehydration normally occur through adjustments in stomatal conductance and chlorophyll maintenance (Cornic and Massacci 1996). The transgenic plants maintained significantly higher stomatal conductance across the period of induced water-deficit stress when compared to the WT plants. In sugarcane, stomatal closure is a common tolerance mechanism that prevents transpiration (Inman-Bamber and Smith 2005). Drought induced a reduction in total chlorophyll content in all the genotypes, as recorded in various sugarcane varieties exposed to drought (Silva et al. 2013; Zhao et al. 2013). Furthermore, under normal or mild stress conditions, all the plants displayed $\mathrm{Fv} / \mathrm{fm}$ values close to 0.75 or higher at 0.81 in some of the transgenic plants, which reflects Photosystem II (PSII) functionality (Bjorkman and Demming 1987; Maxwell and Johnson 2000). However, after long exposure to water-deficit stress (21 days ww), most of the transgenic lines maintained a significantly higher photosynthetic capacity ( $\mathrm{Fv} / \mathrm{fm}$ ratio) than the WT plants, which suggests a unique protection of PSII in the transgenic plants. Similarly, the ectopic expression of $S I Z F 2$, a zinc finger protein containing a B-box domain, enhanced salt tolerance in tomato by delayed senescence and 
(a)
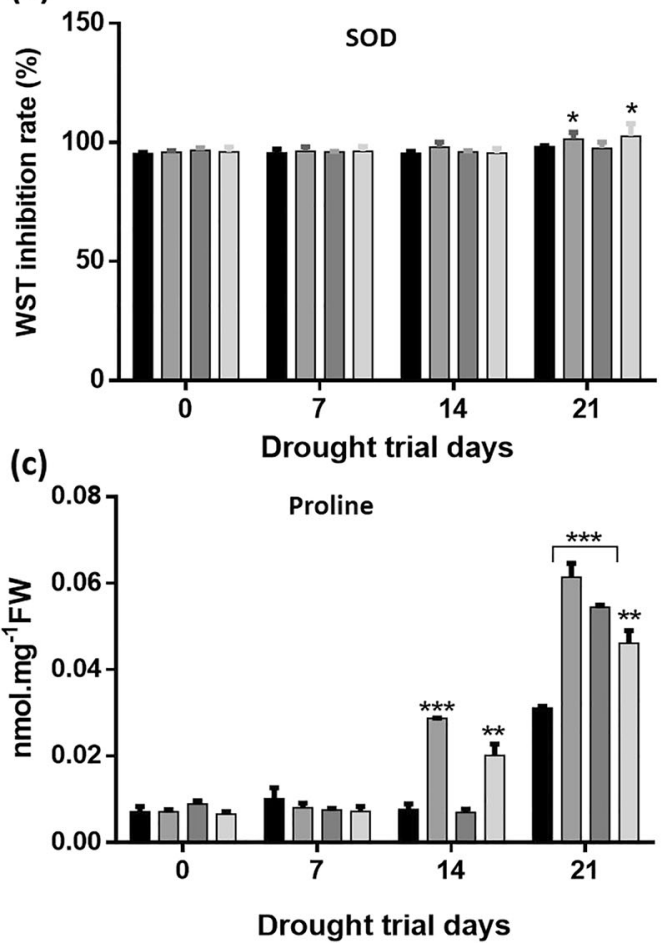

Fig. 8 Antioxidant and osmolyte activities in transgenic (T1.1, T1.6 and T1.8) and WT plants exposed to water-deficit stress. Measurements include a superoxide dismutase (SOD) activity, presented as the rate of WST inhibition; b catalase; c proline content and $\mathbf{d}$ glutathione content.

specifically by the maintenance of photosynthesis (Hichri et al. 2014). Photosynthesis is essential for the maintenance of the entire plant function and for the balance of the resources for growth and stress adaptation in sugarcane (Ferreira et al. 2017).

Plants naturally produce ROS, such as hydrogen peroxide and superoxide, during normal metabolic processes, such as photosynthesis (Hussain et al. 2012), and play crucial roles as signalling molecules (Gill and Tuteja 2010). However, water-deficit conditions promote the production of these molecules to toxic levels, which can destroy cellular components, including DNA, membrane lipids and proteins (Ashraf 2009; Gill and Tuteja 2010; Xie et al. 2019). In this study, the observed enhanced tolerance to drought in the $A t B B X 29$ transgenic plants can, in part, also be attributed to the upregulation of the antioxidant system. The transgenic plants accumulating significantly lower levels of $\mathrm{H}_{2} \mathrm{O}_{2}$ than the WT plants during dehydration, since plants can detoxify ROS through antioxidant defence systems. In addition, MDA levels were also significantly lower in most of the transgenic plants at the end of the drought period. Malondialdehyde is a marker of oxidative stress and results from lipid peroxidation (de Dios Alche 2019). Low levels of lipid peroxidation have been associated with cell survival through the continuous activation of signalling pathways, which results in adaptation and higher antioxidant ability, reflecting increased resistance to water-deficit stress. Thus, the decrease in MDA (b)
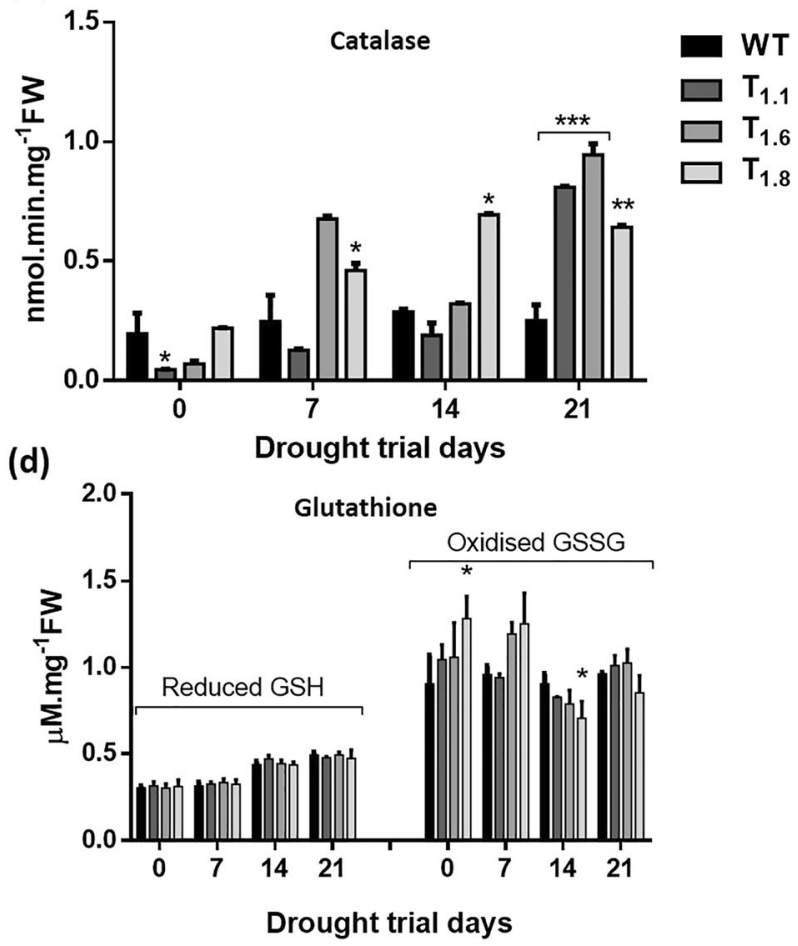

Data is presented as means $\pm \mathrm{SD}$ of three biological replicate $(n=3)$. Asterisks $(*),(* *)$ and $(* * *)$ indicate significant difference between transgenic and WT plants at $p \leq 0.05,0.01$ and 0.001

level and $\mathrm{H}_{2} \mathrm{O}_{2}$ content observed in this study indicated that the transgenic sugarcane plants suffered less oxidative injury compared to the WT plants after drought treatment.

$\mathrm{C} 2 \mathrm{H} 2$ zinc finger TF proteins have been known to support stable ROS levels through enhanced antioxidant scavenging systems in transgenic plants (Davletova et al. 2005; Gadjev et al. 2006; Rizhsky et al. 2004; Huang et al. 2009). A zinc finger protein containing a B-box domain, $M d B B X 10$ from apple, specifically enhanced drought tolerance in the transgenic plants by improving their ability to scavenge reactive oxygen species (Liu et al. 2019). Similarly, when a B-box containing C2H2-type zinc finger protein, PtrZPT2-1 from orange, was overexpressed in tobacco, it decreased ion leakage, MDA content and $\mathrm{H}_{2} \mathrm{O}_{2}$ accumulation after drought treatment in the transgenic plants (Liu et al. 2017). Antioxidant enzymes levels, including SOD and CAT, and the corresponding ROS detoxification genes expression levels furthermore increased in these transgenic plants.

SOD scavenges $\mathrm{O}_{2}{ }^{-}$to generate $\mathrm{H}_{2} \mathrm{O}_{2}$ and oxygen and CAT decomposes $\mathrm{H}_{2} \mathrm{O}_{2}$ to water and oxygen (Mittler 2002). In this study, both SOD and CAT levels increased during drought in the AtBBX29 transgenic plants, while these antioxidant levels stayed mostly constant in the WT plants. The overexpression of ZFP245 and ZFP179 in rice increased activities of SOD and peroxidase in response to multiple stress conditions and resulted in increased stress tolerance (Huang et al. 2009; Sun et al. 2010). In sugarcane, studies have 
showed that the activity of SOD and CAT is genotype-dependent, where increased activity is displayed mostly in sugarcane cultivars tolerant to water-deficit conditions (dos Santos et al. 2015; Hemaprabha et al. 2013; Jangpromma et al. 2012; Sales et al. 2015). These findings also suggest that the overexpression of $A t B B X 29$ may have played a similar role in targeting the expression of antioxidant genes for the removal of ROS and may have enhanced the protection of the transgenic sugarcane from oxidative stress damage.

The biochemical changes caused by $A t B B X 29$ overexpression included increased proline content after drought exposure. Proline is known to provide protection to plants under drought stress by acting as osmolyte, antioxidant and signalling defence molecule responsible for osmotic adjustment, ROS detoxification and protein stabilisation (Yadav et al. 2019; Ashraf and Foolad 2007; Hayat et al. 2012). A B-box containing zinc finger protein is known to enhance plant drought tolerance through increased levels of osmotic adjustment substances. For example, the overexpression of ZFP252 in rice or OSMSR 15 in Arabidopsis enhanced salt and drought tolerance in the transgenic plants with higher proline content, with the plants displaying enhanced transcript levels of P5CS ( $\Delta^{\prime}$-pyrroline-5-carboxylate synthetize), an important gene related to proline glutamate biosynthesis (Xu et al. 2008; Zhang et al. 2016). Previous studies in sugarcane have suggested that the accumulation of high proline content acts as an osmoregulator and an antioxidant when water is limited (Abbas et al. 2014; Cia et al. 2012; de Oliveira et al. 2018; Molinari et al. 2007). A study by Molinari et al. (2007) reported that, in transgenic sugarcane overexpressing P5CS, instead of osmotic adjustment, proline accumulation was increased to enhanced biomass and the photochemical efficiency of PSII under drought conditions was protected.

In conclusion, we found, as a new result that the overexpression of $A t B B X 29$ in sugarcane increased tolerance to drought by delaying the onset of water-deficit stress and maintaining vital photosynthetic processes for longer. It furthermore improved osmotic regulation, upregulated the antioxidative system and limited ROS damage after drought treatment in the transgenic lines by reducing the MDA level and $\mathrm{H}_{2} \mathrm{O}_{2}$ content and increasing the proline level and antioxidant enzyme activity. To understand the role of $A t B B X 29$ in the abiotic stress response in sugarcane in full, further molecular analysis, including the detection of interactive gene expression activity, may provide novel insights into $A t B B X 29$-mediated abiotic stress tolerance worthy of further elucidation in the future.

Supplementary Information The online version contains supplementary material available at https://doi.org/10.1007/s11105-020-01261-8.

Author's Contributions SKP and CVDV planned the study, NM conducted the research, CVDV and SKP contributed to the interpretation of data, NM wrote the first draft, and CVDV finalised editorial inputs.
Funding South African Sugar Association (Grant: S004120) provided research funding and the National Research Foundation of South Africa provided a Master student fellowship (UID: 112996) and research funding under the NRF SA-India Joint Science and Technology Research Collaboration program (Grant 104791).

Data Availability All data and materials support published claims and comply with field standards.

\section{Compliance with Ethical Standards}

Conflict of Interest The authors declare that they have no conflicts of interest.

\section{Ethics Approval Not applicable.}

Consent to Publication All authors agreed with the content and gave explicit consent to submit before submission of the publication.

Code Availability Not applicable.

Open Access This article is licensed under a Creative Commons Attribution 4.0 International License, which permits use, sharing, adaptation, distribution and reproduction in any medium or format, as long as you give appropriate credit to the original author(s) and the source, provide a link to the Creative Commons licence, and indicate if changes were made. The images or other third party material in this article are included in the article's Creative Commons licence, unless indicated otherwise in a credit line to the material. If material is not included in the article's Creative Commons licence and your intended use is not permitted by statutory regulation or exceeds the permitted use, you will need to obtain permission directly from the copyright holder. To view a copy of this licence, visit http://creativecommons.org/licenses/by/4.0/.

\section{References}

Abbas SR, Ahmad SD, Sabir SM, Shah AH (2014) Detection of drought tolerant sugarcane genotypes (Saccharum officinarum) using lipid peroxidation, antioxidant activity, glycine-betaine and proline contents. J Soil Sci Plant Nutr 14(1):233-243

Arnon DI (1949) Copper enzymes in isolated chloroplasts. Polyphenoloxidase in Beta vulgaris. Plant Physiol 24(1):1

Ashraf M (2009) Biotechnological approach of improving plant salt tolerance using antioxidants as markers. Biotechnol Adv 27(1):84-93

Ashraf M, Foolad MR (2007) Roles of glycine betaine and proline in improving plant abiotic stress resistance. Environ Exp Bot 59:206-216

Bartels D, Sunkar R (2005) Drought and salt tolerance in plants. Crit Rev Plant Sci 24:23-58

Bates LS, Waldren RP, Teare ID (1973) Rapid determination of free proline for water-stress studies. Plant Soil 39(1):205-207

Bjorkman O, Demming B (1987) Photon yield of $\mathrm{O}_{2}$ evolution and chlorophyll fluorescence characteristics at $77 \mathrm{~K}$ among vascular plants of diverse origins. Planta 170(4):489-504

Blum A (2005) Drought resistance, water-use efficiency, and yield potential - are they compatible, dissonant, or mutually exclusive? Aust J Agric Res 56:1159-1168

Bower R, Birch RG (1992) Transgenic sugarcane plants via microprojectile bombardment. Plant J 2(3):409-416

Bradford MM (1976) A rapid and sensitive method for the quantitation of microgram quantities of protein utilizing the principle of protein-dye binding. Anal Biochem 72(1-2):248-254 
Cao Y, Meng D, Han Y, Chen T, Jiao C, Chen Y, Jin Q, Cai Y (2019) Comparative analysis of B-Box genes and their expression pattern analysis under various treatments in Dendrobium officinale. BMC Plant Biol 19:245

Chen H, Huang F, Lie Y, Cheng P, Guan Z, Fang W, Chen S, Chen F, Jiang J (2020) Constitutive expression of chrysanthemum $C m B B X 29$ delays flowering time in transgenic Arabidopsis. Can J Plant Sci 100:86-94

Chow PS, Landhäusser SM (2004) A method for routine measurements of total sugar and starch content in woody plant tissues. Tree Physiol 24(10):1129-1136

Chu Z, Wang X, Li Y, Yu H, Li J, Lu Y, Li H, Ouyang B (2016) Genomic organization, phylogenetic and expression analysis of the B-Box gene family in tomato. Front Plant Sci 7:1552

Cia MC, Guimarães ACR, Medici LO, Chabregas SM, Azevedo RA (2012) Antioxidant responses to water deficit by drought-tolerant and sensitive sugarcane varieties. Ann Appl Biol 161:313-324

Cornic G, Massacci A (1996) Leaf photosynthesis under drought stress. In: Baker NR (ed) Photosynthesis and the environment. Advances in photosynthesis and respiration, vol 5. Springer, Dordrecht. https:// doi.org/10.1007/0-306-48135-9_14

Crocco CD, Botto JF (2013) BBX proteins in green plants: insights into their evolution, structure, feature and functional diversification. Gene 531:44-52

Datta S, Hettiarachchi C, Johansson H, Holm M (2007) SALT TOLERANCE HOMOLOG2, a B-box protein in Arabidopsis that activates transcription and positively regulated light-mediated development. Plant Cell 19:3242-3255

Daudi A, O’Brien JA (2012) Detection of hydrogen peroxide by DAB staining in Arabidopsis leaves. Bio-Protocol 2(18):e263. https://doi. org/10.21769/BioProc.263

Davletova S, Rizhsky L, Liang H, Shengqiang Z, Oliver DJ, Coutu J, Shulaev V, Schlauch K, Mittler R (2005) Cytosolic ascorbate peroxidase 1 is a central component of the reactive oxygen gene network of Arabidopsis. Plant Cell 17:268-281

De Dios Alche J (2019) A concise appraisal of lipid oxidation and lipoxidation in higher plants. Redox Biol 23:101136

De Oliveira LAR, Cardoso MN, de Oliveira ACA, Machado CA, Cardoso BT, da Silva AVC, Ledo AS (2018) Effects of in vitro drought stress on growth, proline accumulation and antioxidant defense in sugarcane. J Agric Sci 10(5):134-149

Ding L, Wang S, Song Z-T, Jiang Y, Han J-J, Lu S-J, Li L, Liu J-X (2018) Two B-box domain proteins, BBX18 and BBX23, interact with ELF3 and regulate thermomorphogenesis in Arabidopsis. Cell Rep 25:1718-1728

dos Santos CM, de Almeida SM, Lima GPP, Bortolheiro FP, Brunelli MC, Oliver R et al (2015) Physiological changes associated with antioxidant enzymes in response to sugarcane tolerance to water deficit and rehydration. Sugar Tech 17:291-304

Droge-Laser W, Snoek BL, Snel B, Weiste C (2018) The Arabidopsis bZIP transcription factor family - an update. Curr Opin Plant Biol 45:36-49

Fan XY, Sun Y, Cao DM, Bai MY, Luo XM, Yang HJ, Wei CQ, Zhu SW, Sun Y, Chong K, Wang ZY (2012) BZS1, a B-box protein, promotes photomorphogenesis downstream of both brassinosteroid and light signaling pathways. Mol Plant 5:591-600

Ferreira THS, Tsunada MS, Bassi D, Araújo P, Mattiello L, Guidelli GV, Righetto GL, Gonçalves VR, Lakshmanan P, Menossi M (2017) Sugarcane water stress tolerance mechanisms and its implications on developing biotechnology solutions. Front Plant Sci 8:1077

Gadjev I, Vanderauwera S, Gechev TS, Laloi C, Minkov IN, Shulaev V, Apel K, Inze D, Mittler, Van Breusegem F (2006) Transcriptomic footprints disclose specificity of reactive oxygen species signaling in Arabidopsis. Plant Physiol 141:436-445

Gahlaut V, Jaiswal V, Kumar A, Gupta PK (2016) Transcription factors involved in drought tolerance and their possible role in developing drought tolerant cultivars with emphasis on wheat (Triticum aestivum L.). Theor Appl Genet 129(11):2019-2042
Gangappa SN, Botto JF (2014) The BBX family of plant transcription factors. Trends Plant Sci 19(7):460-470

Gentile A, Dias LL, Matoos RS, Ferreira TH, Menossi M (2015) MicroRNAs and drought responses in sugarcane. Front Plant Sci 6:58

Gill SS, Tuteja N (2010) Reactive oxygen species and antioxidant machinery in abiotic stress tolerance in crop plants. Plant Physiol Biochem 48:909-930

Hammad S, Ali O (2014) Physiological and biochemical studies on drought tolerance of wheat plants by application of amino acids and yeast extract. Ann Agric Sci 59:133-145

Han G, Lu C, Guo J, Qiao Z, Sui N, Qiu N, Wang B (2020) C2H2 zinc finger proteins: master regulators of abiotic stress responses in plants. Front Plant Sci 11:115

Hayat S, Hayat Q, Alyemeni MN, Wani AS, Pichtel J, Ahmad A (2012) Role of proline under changing environments. A review. Plant Signal Behav 7(11):1-11

Heath RL, Packer L (1968) Photoperoxidation in isolated chloroplasts: I. Kinetics and stoichiometry of fatty acid peroxidation. Arch Biochem Biophys 125(1):189-198

Hemaprabha G, Swapna S, Lavanya DL, Sajith B, Venkataramana S (2013) Evaluation of drought tolerance potential of elite genotypes and progenies of sugarcane (Saccharum spp. hybrids). Sugar Tech 15:9-16

Hichri I, Muhovski Y, Zizková E, Dobrev PI, Franco-Zorrilla JM, Solano R, Lopez-Vidriero I, Motyka V, Lutts S (2014) The Solanum lycopersicum zinc finger2 cysteine-2/ histidine-2 repressor-like transcription factor regulates development and tolerance to salinity in tomato and Arabidopsis. Plant Physiol 164:1967-1990

Hiscox JD, Israelstam GF (1979) A method for the extraction of chlorophyll from leaf tissue without maceration. Can J Bot 57(12):1332-1334

Huang X-Y, Chao D-Y, Gao J-P, Zhu M-Z, Shi M, Lin H-X (2009) A previously unknown zinc finger protein, DST, regulates drought and salt tolerance in rice via stomatal aperture control. Genes Dev 23:1805-1817

Huang J, Zhao X, Weng X, Wang L, Xie W (2012) The rice B-box zinc finger gene family: genomic identification, characterization, expression profiling and diurnal analysis. PLoS One 7(10):e48242

Hussain SS, Raza H, Afzal I, Kayani MA (2012) Transgenic plants for abiotic stress tolerance: current status. Arch Agron Soil Sci 58(7):693-721

Inman-Bamber NG, Smith DM (2005) Water relations in sugarcane and response to water deficits. Field Crop Res 92:185-202

Jangpromma N, Thammasirirak S, Jaisil P, Songsri P (2012) Effects of drought and recovery from drought stress on above ground and root growth, and water use efficiency in sugarcane (Saccharum officinarum L.). Aust J Crop Sci 6:1298-1304

Junglee S, Urban L, Sallanon H, Lopez-Lauri F (2014) Optimized assay for hydrogen peroxide determination in plant tissue using potassium iodide. Am J Anal Chem 5(11):730-736

Khanna R, Kronmiller B, Maszle DR, Couplant G, Holm M, Mizuno T, Wu S-H (2009) The Arabidopsis B-Box zinc finger family. Plant Cell 21(11):3416-3420

Kumagai T, Ito S, Nakamichi N, Niwa Y, Murakami M, Yamashino T, Mizuno T (2008) The common function of a novel subfamily of bbox zinc finger proteins with reference to circadian-associated events in Arabidopsis thaliana. Biosci Biotechnol Biochem 72(6):1539-1549

Kumar D, Yusuf MA, Singh P, Sardar M, Sarin NB, Biosciences JMI (2014) Histochemical detection of superoxide and $\mathrm{H}_{2} \mathrm{O}_{2}$ accumulation in Brassica juncea seedlings. Bio-Protocol 4(8):e1108

Last DI, Brettel RIS, Chamberlain DA, Chaudhury AM, Larkin PJ, Marsh EL, Peacock WJ, Dennis ES (1990) pEmu: an improved vector for gene expression in cereal cells. Theor Appl Genet 81:581-588

Li C, Nong Q, Solanki MK, Liang Q, Xie J, Liu X, Li Y (2016) Differential expression profiles and pathways of genes in sugarcane leaf at elongation stage in response to drought stress. Sci Rep 6:25698

Liu N, Ding Y, Fromm M, Avramova Z (2014) Endogenous ABA extraction and measurement from Arabidopsis leaves. Bio-Protocols 4(19):e1257

Liu D, Yang L, Luo M, Wu Q, Liu S, Liu Y (2017) Molecular cloning and characterization of PtrZPT2-1, a ZPT2 family gene encoding a 
Cys2/His2- type zinc finger protein from trifoliate orange (Poncirus trifoliata (L.) Raf.) that enhances plant tolerance to multiple abiotic stresses. Plant Sci 263:66-78

Liu X, Li R, Dai Y, Yuan L, Sun Q, Zhang S, Wang X (2019) A B-box zinc finger protein, MdBBX10, enhanced salt and drought stresses tolerance in Arabidopsis. Plant Mol Biol 99:437-447

Maxwell K, Johnson GN (2000) Chlorophyll fluorescence-a practical guide. J Exp Bot 51(345):659-668

Mikkelsen MD, Thomashow MF (2009) The role for circadian evening elements in cold-regulated gene expression in Arabidopsis. Plant J 60:328-339

Min JH, Chung JS, Lee KH, Kim CS (2015) The CONSTANS-like 4 transcription factor, $A t C O L 4$, positively regulates biotic stress tolerance through an abscisic acid-dependent manner in Arabidopsis. $\mathrm{J}$ Integr Plant Biol 57(3):313-324

Mittler R (2002) Oxidative stress, antioxidants and stress tolerance. Trends Plant Sci 7:405-410

Molinari HBC, Marur CJ, Daros E, De Campos MKF, De Carvalho JFRP, Filho JCB, Pereira LFP, Vieira LGE (2007) Evaluation of the stress-inducible production of proline in transgenic sugarcane (Saccharum spp.): osmotic adjustment, chlorophyll fluorescence and oxidative stress. Physiol Plant 130(2):218-229

Motulsky HJ (2014) Common misconceptions about data analysis and statistics. Naunyn Schmiedeberg's Arch Pharmacol 387(11):10171023

Murashige T, Skoog F (1962) A revised medium for rapid growth and bio assays with tobacco tissue cultures. Physiol Plant 15(3):473-497

Nagaoka S, Takano T (2003) Salt tolerance-related protein STO binds to a Myb transcription factor homologue and confers salt tolerance in Arabidopsis. J Exp Bot 54(391):2231-2237

Nhamo L, Mabhaudhi T, Modi AT (2019) Preparedness or repeated short-term relief aid? Building drought resilience through early warning in southern Africa. Water South Africa 45(1):75-85

Piperidis G, Piperidis N, D'hont A (2010) Molecular cytogenetic investigation of chromosome composition and transmission in sugarcane. Mol Gen Genomics 284:65-73

Putterill J, Robson F, Lee K, Simon R, Coupland G (1995) The CONSTANS gene of Arabidopsis promotes flowering and encodes a protein showing similarities to zinc finger transcription factors. Cell 80:847-857

Rizhsky L, Davletova S, Liang H, Mittler R (2004) The zinc finger protein Zat12 is required for cytosolic ascorbate peroxidase 1 expression during oxidative stress in Arabidopsis. J Biol Chem 279: 11736-11743

Robson F, Costa MM, Hepworth SR, Vizir I, Pineiro M, Reeves PH, Putterill J, Couplant G (2001) Functional importance of conserved domains in the flowering-time gene CONSTANS demonstrated by analyais of mutant alleles and transgenic plants. Plant J 28:619-631

Sahoo S, Awasthi JP, Sunkar R, Panda SK (2017) Determining glutathione levels in plants. Methods Mol Biol 1631:273-277. https://doi. org/10.1007/978-1-4939-7136-7_16

Sales C, Marchiori P, Machado R, Fontenele A, Machado E, Silveira J et al (2015) Photosynthetic and antioxidant responses to drought during sugarcane ripening. Photosynthetica 53:547-554

Sánchez JP, Duque P, Chua NH (2004) ABA activates ADPR cyclase and cADPR induces a subset of ABA-responsive genes in Arabidopsis. Plant J 38(3):381-395

Shalmani A, Jing XQ, Shi Y, Muhammad I, Zhou MR, Wei XY, Chen QQ, Li WQ, Liu WT, Chen KM (2019) Characterization of B-BOX gene family and their expression profiles under hormonal, abiotic and metal stresses in Poaceae plants. BMC Genomics 20:27. https:// doi.org/10.1186/s12864-018-5336-Z
Silva MDA, Jifon JL, dos Santos CM, Jadoski CJ, da Silva JAG (2013) Photosynthetic capacity and water use efficiency in sugarcane genotypes subject to water deficit during early growth phase. Braz Arch Biol Technol 56:735-748

Smart RE, Bingham GE (1974) Rapid estimates of relative water content. Plant Physiol 53(2):258-260

Soitamo AJ, Piippo M, Allahverdiyeva Y, Battchikova N, Aro E-M (2008) Light has a specific role in modulating Arabidopsis gene expression at low temperature. BMC Plant Biol 8:13. https://doi. org/10.1186/1471-2229-8-13

Sun Y, Fan X-Y, Cao D-M, Tang W, He K, Zhu J-Y, He J-X, Bai M-Y, Zhu S, Oh E (2010) Integration of brassinosteroid signal transduction with the transcription network for plant growth regulation in Arabidopsis. Dev Cell 19(5):765-777

Valentovic P, Luxova M, Kolarovic L, Gasparikova O (2006) Effect of osmotic stress on compatible solutes content, membrane stability and water relations in two maize cultivars. Plant Soil Environ 52(4): 184

Wang J, Nayak S, Koch K, Ming R (2013a) Carbon partitioning in sugarcane (Saccharum species). Front Plant Sci 4(201):1-6

Wang Q, Tu X, Zhang J, Chen X, Rao L (2013b) Heat stress-induced BBX18 negatively regulates the thermotolerance in Arabidopsis. Mol Biol Rep 40(3):2679-2688

Xie X, He Z, Chen N, Tang Z, Wang Q, Cai Y (2019) The roles of environmental factors in regulation of oxidative stress in plant. BioMed Research International, Article ID 9732325:1-11. https:// doi.org/10.1155/2019/9732325

Xu D-Q, Huang J, Guo S-Q, Yang X, Bao Y-M, Tang H-J et al (2008) Overexpression of a TFIIIA-type zinc finger protein gene ZFP252 enhances drought and salt tolerance in rice (Oryza sativa L.). FEBS Lett 582:1037-1043

Xu D, Jiang Y, Li J, Holm M, Deng X (2017) The B-box domain protein $B B X 21$ promotes photomorphogenesis. Plant Physiol 176(3):23652375

Yadav AK, Carroll AJ, Estavillo GM, Rebetzke GJ, Pogson BJ (2019) Wheat drought tolerance in the field is predicted by amino acid responses to glasshouse-imposed drought. J Exp Bot 70(18):49314947

Zhang H, Ni L, Liu YP, Wang YF, Zhang AY, Tan MP, Jiang M (2012) The $\mathrm{C} 2 \mathrm{H} 2$-type zinc finger protein $\mathrm{ZFP} 182$ is involved in abscisic acid-induced antioxidant defense in rice. J Integr Plant Biol 54:500 510

Zhang H, Liu Y, Wen F, Yao D, Wang L, Guo J, Ni L, Zhang A, Tan M, Jiang M (2014) A novel rice C2H2-type zinc finger protein, ZFP36, is a key player involved in abscisic acid-induced antioxidant defense and oxidative stress tolerance in rice. J Exp Bot 65:5795-5809

Zhang X, Zhang B, Li MJ, Yin XM, Huang LF, Cui YC, Wang ML, Xia $\mathrm{X}$ (2016) OsMSR15 encoding a rice C2H2-type zinc finger protein confers enhanced drought tolerance in transgenic Arabidopsis. J Plant Biol 59:271-281

Zhang X, Shang F, Huai J, Xu G, Tang W, Jing Y et al (2017) A PIF1/PIF3-HY5-BBX23 transcription factor cascade affects photomorphogenesis. Plant Physiol 174(4):2487-2500

Zhao D, Glaz B, Comstock JC (2013) Sugarcane leaf photosynthesis and growth characters during development of water deficit stress. Crop Sci 53:1066-1075

Publisher's Note Springer Nature remains neutral with regard to jurisdictional claims in published maps and institutional affiliations. 